\title{
'Miracle stents' - a future without restenosis
}

\author{
Huda Hamid*, John Coltart
}

\begin{abstract}
Over the last three decades, percutaneous coronary intervention (PCI) technology has revolutionized the field of cardiology. PCI began in the form of balloon angioplasty, and was followed by coronary stenting. In-Stent restenosis is the main limitation of coronary stenting, and has been delayed to some extent by the development of drug eluting stents. Coronary angioplasty with stenting is currently the most popular non-medical treatment of coronary artery disease therefore solving the problem of in-stent restenosis could change the future role of other types of coronary intervention. This review examines the types of percutaneous coronary interventions, the mechanisms leading up to in-stent restenosis, and how previous and current treatments of in-stent restenosis influence the vascular response to injury.
\end{abstract}

\section{BACKGROUND}

For several decades, coronary artery bypass graft $(\mathrm{CABG})$ and percutaneous transluminal coronary angioplasty (PTCA) have been the main procedures used to treat coronary artery disease. CABG is a surgical procedure whereby an obstruction in the coronary arteries caused by an atherosclerotic plaque can be treated using saphenous vein grafts or arterial grafts such as internal mammary arteries to bypass the obstruction (1).

PTCA was introduced over 20 years ago as an alternative coronary intervention to the more invasive CABG. The procedure involves making small incisions in the vessels of the groin or arm under local anaesthetic where a catheter can be fed through to the obstructed coronary vessel. A balloon attached to the end of the catheter is used to unblock the vessel and consequently restore the blood flow (1).

However, a number of studies in the early 1990s that compared the outcomes of CABG with PTCA revealed

\footnotetext{
* To whom correspondence should be addressed:

Huda Hamid

23 Longthorpe Court Invermead Close

Hammersmith London

W6 0QH
}

higher re-intervention rates with PTCA (2). During PTCA, the balloon is inflated at the site of atherosclerotic narrowing, dilating the vessel lumen, and causing compression of the plaque and stretching of the vessel wall. Thus, the result is fracturing and fissuring of the atheroma due to its inelastic components and an extension into the vessel wall, causing either superficial or deep arterial injury (Figure 1) (3).

The response of vascular tissue to the injury caused by balloon angioplasty accounted for its two major limitations, which were acute vessel closure and restenosis (renarrowing of the vessel). The incidence of acute vessel closure was $3-5 \%$, and would occur within the first 24 hours of the procedure due to vessel dissection or acute thrombus formation (3).

Restenosis can be defined as a reduction in the luminal diameter of more than $50 \%$. It had a high incidence rate of $25-50 \%$ in patients having undergone balloon angioplasty, with the vast majority of patients requiring revascularisation within 6 months (3). This occurred because of elastic recoil and intimal hyperplasia as a response to vascular injury.

Coronary artery stenting was then introduced with the hope that the limitations of balloon angioplasty could be overcome (4). This involved placing a stent, a metal 
meshwork device, into the vascular lumen to keep the vessel open and prevent acute vessel closure and restenosis (5). Coronary stenting was shown to significantly improve the outcome, including a $10 \%$ reduction in restenosis rates compared to angioplasty alone (6).

This paper reviews the definition, pathophysiology, and treatment of in-stent restenosis, as well as its implications in the development of new stent designs.

\section{PROCEDURES FOR BALLOON ANGIOPLASTY AND STENTING}

Under local anaesthetic, a guide catheter is introduced into the femoral artery in the groin or the brachial artery in the arm. The catheter reaches the aorta through the artery, and is lodged within the aorta at the origin of the coronary artery. To identify the areas of narrowing, a radio-opaque contrast is injected into the coronary artery and $\mathrm{x}$-rays are used to produce a continuous image (3).

A guide wire that runs along the middle of the guiding catheter is passed down the coronary artery and through the obstruction. A balloon-tipped catheter is then passed over the guide wire placed at the stenosis and the balloon is inflated. The coronary artery lumen is widened, and the guide catheter, guide wire, and balloon are withdrawn (3).

With coronary stenting, the stenosis may be stented directly or dilated with a balloon before stenting (3). With direct stenting, the stent (a tubular wire mesh) is stretched into a constrained state with a special delivery catheter and then gradually released at the site of the stenosis. The radial forces of the stent on the vascular wall lead to dilation of the vessel.

With a balloon-expandable stent, the balloon is inflated to expand the stent so that it holds the narrowed vessel open. Finally, the balloon is deflated and withdrawn (5).

\section{DEFINITION OF IN-STENT RESTENOSIS}

In-stent restenosis is defined as a decrease in the luminal diameter by greater than $50 \%$ in the stented area of the vessel, similar to post-angioplasty restenosis (PARS). This is known as angiographic restenosis. As with post-angioplasty restenosis, in-stent restenosis also occurs within 6 months of stenting (6).

Clinically, in-stent restenosis can present as recurrent angina or myocardial ischaemia although angiographic restenosis does not always lead to clinical symptoms such as angina. In-stent restenosis can also be defined by the relative length of the restenotic lesion: if the lesion measures less than $10 \mathrm{~mm}$, it is known as focal, whereas if it measures more than $10 \mathrm{~mm}$, it is known as diffuse (6).

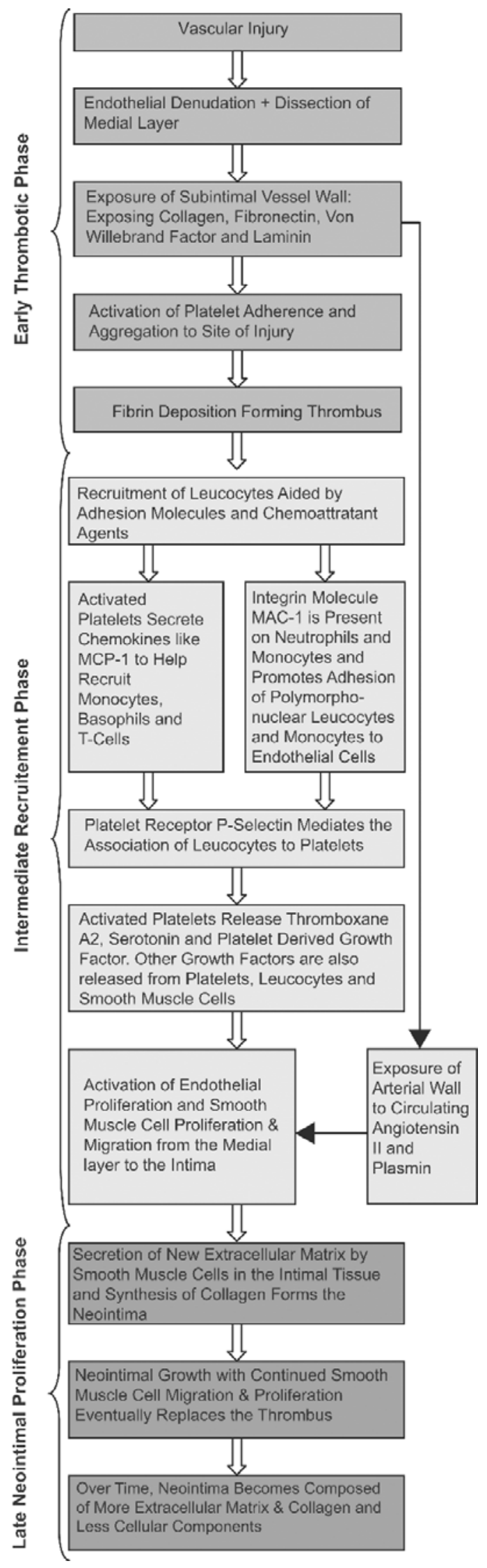




\section{PATHOPHYSIOLOGY OF RESTENOSIS}

Restenosis occurs as a result of the response of the vascular tissue to the injury caused by coronary angioplasty (7). In the case of in-stent restenosis, it is the result of vascular injury that occurs after stenting. The injury caused by insertion of a stent is different from the injury caused by angioplasty alone. This results in differences in the pathophysiological mechanisms that lead to restenosis in response to injury.

The struts of the stent cause deep, focal injury to the vascular tissue whereas the balloon inflation is less controlled in stretching and fracturing the vessel wall. Also, in stenting, the extensive, early thrombus can act as a scaffold whereby cell proliferation and neointimal hyperplasia can occur. Additionally, inserting a stent causes permanent strain on the vessel wall as opposed to the transient strain applied by the balloon. Finally, with stenting, a foreign material remains in the vessel unlike the withdrawal of the balloon in coronary angioplasty (8).

The response to injury hypothesis used to describe the mechanisms that lead to atherosclerosis plays an important role in restenosis. In this hypothesis, repeated vascular injury causes endothelial denudation and subsequently results in platelet adhesion, thrombus formation and monocyte infiltration (7).

The leukocytes and platelets release cytokines, vasoactive agents, and growth factors, which promote an inflammatory response (9). Platelet-derived growth factor can lead to smooth muscle cell proliferation and migration into the intima to form the neointima (10).

Three mechanisms that lead to the development of restenosis are elastic recoil, neointimal proliferation, and negative remodelling (11). Inflammation plays an important role in linking the early vascular injury of deendothelialization and thrombus deposition, to the more chronic response of healing whereby cell proliferation, cell migration, and extracellular matrix synthesis leads to neointimal growth and a reduction in lumen size (10).

\section{Elastic Recoil}

The intimal, medial, and adventitial layers of the coronary arteries are separated by elastin fibres, namely the internal and external elastic lamina. Elastic recoil is a passive process that occurs in seconds to minutes as a result of the elastic laminae applying opposing force to the overstretch caused by balloon inflation. This reduces the lumen by up to $40 \%(12,13)$.

In studies comparing balloon-injured and stented arteries, the rigid scaffolding of the stent prevented elastic recoil and subsequently stented arteries were found to have a much larger initial gain in lumen size $(14,15)$.

\section{Inflammatory Changes}

Inflammatory response within the vessel wall following PCI can be divided into three stages: early thrombotic phase (hours to days), intermediate recruitment phase (3-10 days), and the late neointimal proliferation phase (weeks to months) (11).

\section{Early Thrombotic Phase}

Vascular injury caused by angioplasty and stenting leads to endothelial denudation. Consequently, exposure of the subintima of the vessel wall activates platelet aggregation, which is followed by fibrin deposition and formation of a thrombus $(11,13)$. With stents, the injury is deeper and more focal, and thick platelet rich mural thrombi form on the stent struts (8).

\section{Intermediate Recruitment Phase}

In this phase, there is recruitment of leukocytes aided by adhesion molecules and chemoattractant agents (6). Firm adhesion and transplatelet migration of the leukocytes are aided by the integrin class of adhesion molecules (16). For example, integrin molecule MAC-1 (CD11b/CD18) promotes the adhesion of polymorphonuclear leukocytes and monocytes to the endothelial cells (10). MAC-1 expression is increased following stenting (17).

Chemokines are chemoattractant cytokines, which lead to further leukocyte recruitment and infiltration. The monocyte chemoattractant protein (MCP-1) is an example of a chemokine secreted by activated platelets (18). MCP-1 expression has been found to be elevated in endothelial cells and vascular smooth muscle cells following stenting (19) and levels of MCP-1 have been shown to be persistently elevated in patients with restenosis (20).

Activated platelets release factors that activate endothelial proliferation and smooth muscle migration from the media to the intima (11). There is also exposure of the arterial wall to circulating angiotensin II and plasmin (13). Medial smooth muscle cells undergo phenotypic modification from contractile to 'synthetic', which leads to their migration to the intima and subsequent proliferation there (6).

\section{Late Neointimal Proliferation Phase}

Formation of new extracellular matrix in the intimal tissue is coupled with synthesis of collagen to form the neointima (6).

Over time, the thrombus is replaced by the neointima and this increases up to 3 months after the procedure (11). However, over subsequent months the neointimal hyperplasia becomes composed of more extracellular matrix and less cellular components (6). 


\section{Negative Remodelling}

Vascular remodelling consist of the compensatory changes that occur to the arterial size due to expansion of the media and external elastic membrane. "Positive remodelling" describes expansion in the external elastic membrane area, and "negative remodelling" describes shrinkage of the external elastic membrane at the lesion site (12).

Examination of restenosis after experimental angioplasty revealed that arterial remodelling in the form of chronic constriction correlated more with restenosis after angioplasty than neointimal-medial growth (21). Intravascular ultrasound studies show that negative remodelling accounts for $2 / 3$ of lumen loss in restenosis following angioplasty (22).

Stenting, however, was found to cause greater neointimal growth but prevented arterial remodelling. Their overall benefit over angioplasty was attributed to the larger initial gain in lumen size (23).

Oxidative stress is increased post angioplasty and may also be involved in constrictive remodelling by enhancing the breakdown of nitric oxide, a vasodilator, thereby contributing to endothelial dysfunction (24).

\section{TREATMENT OF IN-STENT RESTENOSIS}

Prior to the relatively recent introduction of drug eluting stents, brachytherapy was the only treatment effective in significantly reducing in-stent restenosis. The mechanisms that govern these treatments are described below.

\section{Brachytherapy}

This non-pharmacological treatment delivers intracoronary sources of $\beta$ or $\gamma$ radiation thereby inhibiting cell proliferation in both media and adventitia, reducing both neointimal accumulation and adventitial myofibroblast accumulation.

Intracoronary brachytherapy also prevents constrictive remodelling thought to be a result of reduction in the healing process and can even induce positive remodelling resulting in luminal enlargement. In the SCRIPPS trial, catheter-based brachytherapy was shown to reduce restenosis rates and this was maintained up to three years (25).

However, there are serious limitations to this treatment. One of these is edge restenosis whereby stenosis occurs at the ends or outside the stents, which could be a proliferative effect of low radiation doses on damaged tissue. Late thrombosis can also occur resulting in higher rates of late myocardial infarction.

Other limitations include failure of healing of medial dissections, acceleration of neointimal thickening at some doses or after chronic therapy and delayed reendothelialization. This type of non-specific treatment is able to target multiple mechanisms of restenosis but the non-specificity also limits this treatment by inhibiting the healing process (13).

\section{Drug Eluting Stents}

The introduction of drug eluting stents has been seen as another breakthrough in percutaneous coronary intervention. This is because of the dramatic reduction in restenosis rates not achieved by any previous treatments. Clinical studies showed rates of $5 \%$ or lower (26).

Drug eluting stents achieve these rates by inhibiting multiple biological processes that lead to restenosis. The scaffolding of the stent prevents recoil while the drugs delivered work on the surrounding tissue to prevent neointimal hyperplasia. Also drug eluting stents can deliver higher concentrations of a drug locally without systemic effects (11).

\section{Rapamycin (Sirolimus)}

Rapamycin modulates immune function and acts on T-lymphocyte activation and cell proliferation. It enters cells easily because of its lipophilic property and then binds to an intracellular receptor called FKBP12. This complex then increases cellular cyclin dependent kinase inhibitor (CDKI) p27 and inhibits the action of retinoblastoma protein $(\mathrm{pRb})$, which regulates vascular smooth muscle cell proliferation $(11,13)$.

Inhibition of vascular smooth muscle cell proliferation and migration occurs as a result of growth arrest between G1 and S phases of the cell cycle. Rapamycin also inhibits inflammation after injury by inhibiting T-lymphocyte proliferation and activation. The biological effects of rapamycin lead to overall inhibition of neointimal formation thereby reducing restenosis $(11,13)$.

\section{Paclitaxel}

Paclitaxel belongs to a group of drugs called taxanes which are antiproliferatives used in cancer treatment. It inhibits cell proliferation and migration by promoting polymerisation of tubulin dimers and subsequently stabilising microtubules into an assembled state (11).

Microtubule disassembly is required for transition between G2 and M phase of the cell cycle. Therefore cell proliferation (such as in smooth muscle cells) is inhibited by this drug. It is also lipophilic and therefore rapidly taken up by cells. However, by altering the cytoskeletal structure, Paclitaxel exerts long-lasting effects in vascular smooth muscle cells (13).

Clinical trials have shown the positive outcomes of using this drug, such as the ELUTES and ASPECT trials which revealed a dose-dependent reduction in percent diameter stenosis (11). 
The multiple actions of rapamycin and paclitaxel suggest they are the ideal agents to inhibit multiple processes leading to in-stent restenosis. However, one of the main concerns about this non-specific feature of both brachytherapy and drug eluting stents is the reduction in the healing process, which leads to loss of reendothelialization and possible late thrombosis (13).

\section{DES vs. BMS}

The reduction in the need for new revascularisation procedures has been the main clinical benefit of drug eluting stents (DES) over bare metal stents (BMS), shown in a great number of randomized controlled trials since 2002 (27). This finding resulted in their widespread use with estimates of DES accounting for more than $90 \%$ of stents used in the USA and Switzerland (28).

Initial concerns over increased stent thrombosis with DES compared to BMS were followed by several reports evaluating the safety of the drug eluting stents. These reports showed no significant differences between DES and BMS in the incidence of stent thrombosis during the first year of follow-up (29).

However, there has been a growing concern about the long-term safety of DES. At the World Congress of Cardiology in September 2006, the results of two independent meta-analyses were presented, showing a higher incidence of death and MI in the first generation DES compared to BMS at the latest follow-up of four years and this is thought to reflect the incidence of stent thrombosis. This has led to a heated debate about the widespread use of DES (28).

A series of meta-analyses evaluated the risk of very late stent thrombosis ( $>12$ months) with the use of DES. One of these comprised of 6675 patients from 14 clinical trials and found that the incidence of very late stent thrombosis ( $>1$ year post procedure) was low but that there was an increased risk of late thrombosis with DES (30). In another meta-analysis comprising nine double-blind trials and assessing the safety of sirolimus and paclitaxel-eluting coronary stents, stent thrombosis was more common in both DES compared with BMS after 1 year. However, there was no significant difference in the cumulative rates of death or MI at four years.

Recently, several meta-analyses have been carried out and some of these have found there to be no significant differences between the use of BMS and DES in the rates of death, MI or stent thrombosis.

One recent meta-analysis of seven randomized trials comparing DES and BMS in acute myocardial infarction (AMI), involved a total of 2357 patients with a follow up of 8-12 months. The results showed the DES to reduce the need for revascularisation significantly in patients with AMI with no difference in the incidence of death or MI compared to BMS. Furthermore the DES were not found to increase the risk of stent thrombosis at 1-year follow-up. However, there was no data available on the higher risk group of patients and the follow-up was limited to 12 months (32).

Another recent meta-analysis of four randomized trials, comprising 1748 patients, compared the use of sirolimus-eluting stents (SES) with BMS, with followup of four years. Three of these trials included patients with higher risk and more complex lesions. The authors concluded there were no significant differences between the two stents in the rates of death, MI or stent thrombosis (27).

The evidence remains inconclusive about the risk of stent thrombosis in DES and an update of the current evidence regarding the safety of DES is due to be presented at the next World Congress of Cardiology in September 2007.

\section{New Developments}

Within the stent industry there has been ongoing research aimed at developing a type of stent that will overcome the limitations of both bare metal stents and first generation drug eluting stents. Thus the goal is to prevent in-stent restenosis while promoting healing and reendothelialization of the vessel to prevent late thrombosis.

The most promising of these new types of stents is the biodegradable stents. The idea behind these is that having widened the lumen of the vessel, the stent remains in situ only for the time needed to prevent elastic recoil and constrictive remodelling. Thereafter, the stent is slowly absorbed and metabolised by the vessel until it disappears allowing reendothelialization to take place (33).

Currently bioabsorbable magnesium stents are in clinical trials. In a recent multicentre study, results showed that the stents can achieve an immediate lumen enlargement similar to conventional metallic stents and can be safely degraded after four months. Ongoing research in this domain includes modifications to prolong the degradation period (34).

Furthermore, biodegradable stents can also be designed to deliver drugs and these biodegradable drug eluting stents would be able to prevent in-stent restenosis with the added advantage of preventing late stent thrombosis (35). The stents may also be used as a delivery vehicle for genes to exert a beneficial antiproliferative effect on the arterial wall cells. Examples include genes for endothelial nitric oxide synthase and vascular endothelial growth factor. Gene transfer is now in phase I studies in humans (36). 
Drug eluting stents are also undergoing development so that the next generation of DES overcomes the limitations of the first generation such as late thrombosis. Recently, one of these DES has been put forward to the Food and Drug Administration for market approval in the U.S. This is the Xience V everolimus-eluting stent, which has a thin metal platform and the new drug has been shown to reduce tissue proliferation in coronary vessels. Furthermore, results of the clinical trials (SPIRIT) demonstrated no stent thrombosis at 3 years (37).

Following on from this, a bioabsorbable everolimuseluting stent has been developed and is also undergoing clinical trials (ABSORB). In a recent trial of 30 patients, at 30 days the device was successful in $93.5 \%$ of all cases. There was also $100 \%$ safety as no patients experienced a major adverse coronary event or stent thrombosis. At 180 days, 3.3\% of patients had major adverse coronary events and no stent thrombosis. Unfortunately there was a restenosis rate of $11.5 \%$ and this was due to shrinkage of the stent. Currently the stent is undergoing further development to resolve this issue (38).

The other type of DES that is being developed is the EPC-capturing stent where the stent is coated with an antibody $(\mathrm{CD} 34+)$ that attracts endothelial progenitor cells (EPCs). The goal of this DES is to promote endothelial growth so the artery can heal faster to prevent in-stent restenosis. In a recent study testing this new DES, results showed excellent procedural success with $3.7 \%$ target vessel revascularization at 6 months (38).

With the advent of newer and better developed DES, the problems of in-stent restenosis and late thrombosis could be a thing of the past with better long-term outcomes for patients treated with the next generation of DES.

\section{CONCLUSION}

Prior to drug eluting stents, brachytherapy was the only treatment that proved effective in reducing restenosis. However brachytherapy showed significant side effects and therefore the search was still on for a solution to the problem of in-stent restenosis.

This came with the introduction of drug eluting stents, which has revolutionized coronary stenting. They have been hailed as 'miracle' stents due to their almost zero in-stent restenosis rate. The safety concerns have been mainly directed at the first generation of DES. Therefore, current advancements in the field of DES could increase the efficacy and safety of future DES.

\section{REFERENCES}

1. Bakhai A, Hill RA, Dundar Y, Dickson R, Walley $T$. Percutaneous Transluminal Coronary Angioplasty with Stents
Versus Coronary Artery Bypass Grafting for People with Stable Angina or Acute Coronary Syndromes. Cochrane Database Syst Rev 2005; (1):CD004588

2. Reul, RM. Will Drug-eluting Stents Replace Coronary Artery Bypass Surgery? Tex Heart Inst J 2005; 32(3): 323-330

3. Grech ED. ABC of Interventional Cardiology: Percutaneous Coronary Intervention II: the Procedure. BMJ 2003; 326(73

4. Ruygrok PN, Serruys PW. (1996). Intracoronary stenting. From concept to custom., Circulation, Sep 1;94(5):882-90.99):113740.

5. Yang XM, Manninen H, Matsi P, Soimakallio S. (1991) Percutaneous endovascular stenting: development, investigation and application. Eur. J. Radiol. NovDec;13(3):161-73.

6. Mitra AK, Agrawal DK. (2006). In stent restenosis: bane of the stent era. J Clin Pathol. Mar;59(3):232-9.

7. Faxon DP, Sanborn TA, Haudenschild CC. (1987) Mechanism of angioplasty and its relation to restenosis. Am J Cardiol., Jul 31;60(3):5B-9B

8. Edelman ER, Rogers C. (1996) Hoop dreams. Stents without restenosis. Circulation. Sep 15;94(6):1199-202.

9. Stocker R, Keaney JF Jr. (2004) Role of oxidative modifications in atherosclerosis. Physiol Rev. Oct;84(4):1381-478.

10. Welt FG, Rogers C. (2002) Inflammation and restenosis in the stent era. Arterioscler Thromb Vasc Biol. Nov 1;22(11):1769-76.

11. White CJ, (2005) Drug-Eluting Stents Advanced Applications for the Management of Coronary Disease. Taylor \&Francis. pp. 7-11, 15, 19, 22-23, 74.

12. Schoenhagen P, Ziada KM, Vince DG, Nissen SE, Tuzcu EM. (2001) Arterial remodeling and coronary artery disease: the concept of "dilated" versus "obstructive" coronary atherosclerosis. J Am Coll Cardiol. Aug;38(2):297-306.

13. Bennett MR. (2003) In-stent stenosis: pathology and implications for the development of drug eluting stents. Heart, Feb;89(2):218-24.

14. Fischman DL, Leon MB, Baim DS, Schatz RA, Savage MP, Penn I, Detre K, Veltri L, Ricci D, Nobuyoshi M, et al. (1994) A randomized comparison of coronary-stent placement and balloon angioplasty in the treatment of coronary artery disease. Stent Restenosis Study Investigators. N Engl J Med., Aug 25;331(8):496-501.

15. Serruys PW, de Jaegere P, Kiemeneij F, Macaya C, Rutsch W, Heyndrickx G, Emanuelsson H, Marco J, Legrand V, Materne P, et al. (1994) A comparison of balloon-expandable-stent implantation with balloon angioplasty in patients with coronary artery disease. Benestent Study Group. N Engl J Med. Aug 25;331(8):489-95.

16. Inoue T, Sakai Y, Hoshi K, Yaguchi I, Fujito T, Morooka S. (1998) Lower expression of neutrophil adhesion molecule indicates less vessel wall injury and might explain lower restenosis rate after cutting balloon angioplasty. Circulation, Jun 30;97(25):2511-8.

17. Fuster V, Falk E, Fallon JT, Badimon L, Chesebro JH, Badimon JJ. (1995) The three processes leading to post PTCA restenosis: dependence on the lesion substrate. Thromb Haemost. Jul;74(1):552-9

18. Rollins BJ. (1996) Monocyte chemoattractant protein 1: a potential regulator of monocyte recruitment in inflammatory disease. Mol Med Today. May;2(5):198-204.

19. Furukawa Y, Matsumori A, Ohashi N, Shioi T, Ono K, Harada A, Matsushima K, Sasayama S. (1999) Anti-monocyte chemoattractant protein-1/monocyte chemotactic and activating factor antibody inhibits neointimal hyperplasia in injured rat carotid arteries. Circ Res. Feb 19;84(3):306-14.

20. Cipollone F, Marini M, Fazia M, Pini B, Iezzi A, Reale M, Paloscia L, Materazzo G, D'Annunzio E, Conti P, Chiarelli F, Cuccurullo F, Mezzetti A. (2001) Elevated circulating levels of monocyte chemoattractant protein-1 in patients with restenosis 
after coronary angioplasty. Arterioscler Thromb Vasc Biol. Mar;21(3):327-34.

21. Lafont A, Guzman LA, Whitlow PL, Goormastic M, Cornhill JF, Chisolm GM. (1995) Restenosis after experimental angioplasty. Intimal, medial, and adventitial changes associated with constrictive remodeling. Circ Res. Jun;76(6):996-1002

22. Mintz GS, Popma JJ, Pichard AD, Kent KM, Satler LF, Wong C, Hong MK, Kovach JA, Leon MB. (1996) Arterial remodeling after coronary angioplasty: a serial intravascular ultrasound study. Circulation, Jul 1;94(1):35-43.

23. Hoffmann R, Mintz GS, Dussaillant GR, Popma JJ, Pichard AD, Satler LF, Kent KM, Griffin J, Leon MB. (1996) Patterns and mechanisms of in-stent restenosis. A serial intravascular ultrasound study. Circulation, Sep 15;94(6):1247-54

24. Lafont A, Durand E, Samuel JL, Besse B, Addad F, Levy BI, Desnos M, Guerot C, Boulanger CM. (1999) Endothelial dysfunction and collagen accumulation: two independent factors for restenosis and constrictive remodeling after experimental angioplasty. Circulation, Sep 7;100(10):1109-15

25. Kavanagh CA, Rochev YA, Gallagher WM, Dawson KA, Keenan AK. (2004) Local drug delivery in restenosis injury: thermoresponsive co-polymers as potential drug delivery systems. Pharmacol Ther. Apr;102(1):1-15

26. Holmes DR Jr, Leon MB, Moses JW, Popma JJ, Cutlip D, Fitzgerald PJ, Brown C, Fischell T, Wong SC, Midei M, Snead D, Kuntz RE. (2004) Analysis of 1-year clinical outcomes in the SIRIUS trial: a randomized trial of a sirolimus-eluting stent versus a standard stent in patients at high risk for coronary restenosis. Circulation, Feb 10;109(5):634-40

27. Spaulding C, Daemen J, Boersma E, Cutlip DE, Serruys PW. (2007) A pooled analysis of data comparing sirolimus-eluting stents with bare-metal stents. N Engl J Med. Mar 8;356(10):98997

28. European Society of Cardiology Congress News. (2006) The drug eluting stents debate - Hot Line Session Results. http://www.escardio.org/vpo/News/events/wcc_ drugelutingstents_events.htm September 5, 2006. Accessed
18 th June, 2007.

29. Luscher TF, Steffel J, Eberli FR, Joner M, Nakazawa G, Tanner FC, Virmani R. (2007) Drug-eluting stent and coronary thrombosis: biological mechanisms and clinical implications. Circulation. Feb 27;115(8):1051-8.

30. Bavry AA, Kumbhani DJ, Helton TJ, Borek PP, Mood GR, Bhatt DL. (2006) Late thrombosis of drug-eluting stents: a metaanalysis of randomized clinical trials. Am J Med. Dec;119(12):1056-61.

31. Stone GW, Moses JW, Ellis SG, Schofer J, Dawkins KD, Morice MC, Colombo A, Schampaert E, Grube E, Kirtane AJ, Cutlip DE, Fahy M, Pocock SJ, Mehran R, Leon MB. (2007) Safety and efficacy of sirolimus- and paclitaxel-eluting coronary stents. N Engl J Med. Mar 8;356(10):998-1008.

32. Pasceri V, Patti G, Speciale G, Pristipino C, Richichi G, Di Sciascio G. (2007) Meta-analysis of clinical trials on use of drug-eluting stents for treatment of acute myocardial infarction. Am Heart J. May;153(5):749-54.

33. Smith EJ, Jain AK, Rothman MT. (2006) New developments in coronary stent technology. J Interv Cardiol. 2006 Dec;19(6):493-9.

34. Erbel R, Di Mario C, Bartunek J, et al. (2007) Temporary scaffolding of coronary arteries with bioabsorbable magnesium stents: a prospective, non-randomised multicentre trial. Lancet. Jun 2;369(9576):1869-75.

35. Waksman R. (2006) Update on bioabsorbable stents: from bench to clinical. J Interv Cardiol. Oct;19(5):414-21.

36. Bhargava B, Karthikeyan G, Abizaid AS, Mehran R. (2003) New approaches to preventing restenosis. BMJ. Aug 2;327(7409):274-9.

37. Abbott Press Release. (2007) Abbott submits XIENCETM V Everolimus Eluting Coronary Stent System Application for U.S. FDA Approval. http://www.abbott.com/global/url/pressRelease/en US/60.5:5/Press_Release_0474.htm June 1, 2007. Accessed 19 th June 2007.

38. Mitka M. (2007) New drug-eluting stents under study. JAMA. May 16;297(19):2064-7.

Huda Hamid (Main Author)- 3rd year medical student, King's College London. Current interests include cardiology and physiology and hope to specialize in the cardiology field.

John Coltart, MD FRCP FACC FESC MRCS, (Expert Co-Author) is a Consultant Cardiologist at St Thomas' Hospital, London. His research interests include interventional cardiology, ischaemic heart disease, and thrombotic cerebral disease. 